\title{
Mathematical Model Development and 3D Printing of Cylindrically Shaped Biofilm Carrier Media from Recycled Plastic Waste for Wastewater Treatment
}

\author{
Selamo Basile Nyuysoni1 ${ }^{*}$, James M. Mutua², Patrick G. Home ${ }^{3}$ \\ ${ }^{1}$ Department of Mechanical Engineering, Pan African University Institute for Basic Sciences, Technology and Innovation, Nairobi, \\ Kenya \\ ${ }^{2}$ Department of Mechanical Engineering, Jomo Kenyatta University of Agriculture and Technology, Nairobi, Kenya \\ ${ }^{3}$ Department of Soil, Water and Environmental Engineering, Jomo Kenyatta University of Agriculture and Technology, Nairobi, \\ Kenya \\ Email: ^selamobasile@yahoo.com
}

How to cite this paper: Nyuysoni, S.B., Mutua, J.M. and Home, P.G. (2022) Mathematical Model Development and 3D Printing of Cylindrically Shaped Biofilm Carrier Media from Recycled Plastic Waste for Wastewater Treatment. Journal of Environmental Protection, 13, 15-31. https://doi.org/10.4236/jep.2022.131002

Received: November 18, 2021

Accepted: January 9, 2022

Published: January 12, 2022

Copyright ( 2022 by author(s) and Scientific Research Publishing Inc. This work is licensed under the Creative Commons Attribution International License (CC BY 4.0).

http://creativecommons.org/licenses/by/4.0/ (c) (i) Open Access

\begin{abstract}
Wastewater management and purification remain one of the greatest problems of mankind. The biological wastewater treatment technique uses a biofilm media carrier where microorganisms attach themselves to the surface. This biofilter is usually made from virgin plastic pellets and can also be produced from recycled waste plastic and used in wastewater treatment. The need to treat water using low-cost carrier media has led to finding alternative sources of materials for biofilter manufacturing. Therefore, this work is centered on the recycling of waste plastic to make filaments which are then used for 3D printing of a high specific surface area (SSA) less clogging biofilm carrier through the parametric redesign. In the current study, the polypropylene material was recycled to make a $2.85 \mathrm{~mm}$ diameter filament compatible with the Ultimaker S3. Moreover, analytical models and governing equations were developed for the design of the K3 Kaldnes and MB3 media. Empirical surface area (SA), specific surface area, and volume of the respective carriers were determined using the model developed. SolidWorks was used to design and evaluate the same parameters which were then compared to model results. The errors in SSA obtained from the model with respect to the SolidWorks results for both the K3 Kaldnes and MB3 media were $0.34 \%$ and $0.76 \%$ respectively. With these small error margins, the model can serve as a tool and guideline for the designing of cylindrically shaped carriers. By transforming plastics into biofilters, waste plastics are mopped up reducing pollutions.
\end{abstract}


Consequently, the deployment of such biofilters will enhance efficient wastewater treatment for a cleaner environment and the wellbeing of human race.

\section{Keywords}

Specific Surface Area, Recycling, Cylindrically Shaped Carriers, Clogging, Passage Diameter

\section{Introduction}

Pollution remains one of the world's critical problems major sources of water contamination which leads to water pollution are oil pollution, atmospheric deposition, global warming, radioactive waste, underground storage leakage, industrial waste, marine dumping, sewage and wastewater [1]. If appropriate and efficient methods are not used in mitigating these pollutions, it could result in illnesses, death of mankind, and other marine habitats. Physical, mechanical, chemical, and biological methods are used in wastewater treatment. The biological technique is achieved by using biofilm media carriers produced from virgin plastic pellets. These pellets are extruded to make standard filaments for the 3D printing of biofilters. Therefore, in the recycling of plastics, the plastic wastes are collected, processed, then ground to make pellets [2]. Although most plastics can be recycled, not all recycled plastics can be used to make filaments. There are generally seven categories of plastic generally recycled which include low-density polyethylene (LDPE), polyethylene terephthalate (PET), primarily polycarbonate (PC), high-density polyethylene (HDPE), polyvinyl chloride (PVC), polypropylene, and polystyrene (PS) [3] [4].

In order to achieve efficient wastewater treatment, two factors are considered. These include factors during the design phase and those during the treatment process. The specific surface area (SSA) is one of the key parameters which should be considered in the design of any carrier media. Besides, several other factors such as porosity, clogging, toxicity, void ratio, dynamics, density, surface roughness, passage diameter are considered in the design process to make sure the biofilters have a higher SSA but are less susceptible to clogging. Various researchers have tried to optimize the design of these carrier media with respect to the aforementioned factors, but most biofilters manufactured undergo clogging during operation and this reduces the efficiency of the wastewater treatment system [5] [6].

The primary plastic materials used for fused deposition include polypropylene (PP), polycarbonate, acrylonitrile butadiene styrene (ABS), polyamide, and polyethylene (PE) [5] [6] [7] [8]. Most materials in existence can act as biofilm carrier media. In the selection of the best material, the chemical properties of the material should not compromise and hinder the growth of the microorganisms. In their study, Martinez-Huerta, et al. [9] concluded that thermoplastic polymers like polyethylene (PE), polypropylene (PP) or polystyrene (PS) can be used 
to manufacture biofilm carriers since they offer the best mechanical, physical and chemical properties during wastewater treatment. Moreover, the lifespan and usage of PE and PP are between 10 - 15 years and are preferred to be used as carrier media since they are also relatively cheaper [10]. Even though high density polyethylene (HDPE) is extremely resistant to corrosion, PP despite having a lower density is most rigid and maintains the shape of the carrier at temperatures even more than $100^{\circ} \mathrm{C}$ [9]. Most biofilters manufactured are from virgin pellets and there is still an opportunity to explore biofilter materials manufactured using recycled plastic materials. 3D printing filaments can be fabricated from these recycled plastic pellets. In this research work, recycled PP plastic is used to make pellets. These pellets are then extruded to make a $2.85 \mathrm{~mm}$ standard filament diameter for 3D printing of carrier media.

The SSA is the most critical factor in the design of biofilm carrier media because this factor is associated with clogging when the SSA is very high SSA. The SSA is the most important factor that determines the performance of the biofilm carrier in the MBBR (Moving Bed Biofilm Reactor) system and it is expressed as the ratio of the total surface area to the bulk volume [9] [10] [11] [12]. A higher SSA is favorable because it enables more microorganisms to attach themselves to the surface for enhanced bio decomposition of the wastewater. Gabriel, et al. [5] suggested that, the efficiency and performances of the available commercial carrier media can be increased by altering the media design through topology optimization thereby improving the SSA.

Since the SSA is directly proportional to clogging, the aspect of clogging should be considered in the design phase. This is basically the blockage of the pore spacing of the biofilm carrier media which reduces the efficiency during the wastewater treatment process. Usually, if the spacings of the interior cavities are less than the passage diameter $(d)$, clogging will occur. This phenomenon is mainly influenced by the growth of biofilm and solids particles present in the wastewater. In the presence of excess biofilm growth, the internal cavity pores will be filled with biofilm leading to clogging [8] [13]. In addition, lack of primary treatment on the wastewater to remove initial suspended solid particles leads to blockage of the internal cavities resulting in clogging. Research has been conducted to find ways of minimizing this phenomenon which is always common during the MBBR treatment process. Elliot et al. [6] considered the clogging of the spherical gyroid and estimated that the minimum hole or passage diameter should be $1500 \mu \mathrm{m}$. The minimum passage diameter that results in minimized clogging should be $2.5 \mathrm{~mm}$ for cylindrical carriers [9]. From this basis, a mathematical model can be developed for the design of cylindrical carriers. In the current study mathematical models and governing equations were developed for the design of both the MB3 and K3 Kaldnes carrier media.

The dynamics and buoyancy of the carrier media are another factor to be considered. It should be able to maneuver and rotate easily throughout the entire MBBR tank. This will allow ease of rotation in all directions in the tank. The 
flow velocities in the inner face of the carrier media is dynamically altered by the geometry and orientation [14]. Generally, smaller biofilters are more efficient than bigger biofilters as the interaction volume is higher in small sized biofilters. Studies have shown that bacteria can attach on porous and non-porous media characterized by unique shapes, cylindrical with hollow duct, spherical, granular, flat chip, disc-shaped, star-shaped, fibrous, ellipsoid shaped, parabolic shape, cubic, hollow square spiral, spindle shape, and $\mathrm{O}$ ring. Most of these shapes have a hollow duct to increase active mass transport area [15] [16]. It is commonly known that two carrier media of different sizes can have the same SSA, but the one with the small size is preferred for the wastewater treatment exercise. This is because, the smaller the size of the carrier media, the higher the surface area and the higher the interaction volume during the wastewater treatment process. Since the size and shape affect the dynamics of the media, these two factors do not seem to be significant as long as the effective surface area is the same [10] [15].

The technique used in the manufacture of the carriers is a critical factor and should be taken into consideration. Most carriers are manufactured using injection molding or extrusion of plastics because of their fastest and lower cost of production. Even though these methods are considerably cheaper and faster, they are most efficient for carriers with less complex shapes like the K1 Kaldnes and MB3 media. When it comes to carriers with more complex shapes and smaller sizes, injection molding is preferred since it provides a good surface finish, saves time and can manufacture more biofilters within a shorter period of time [7] [13]. Since material texture, roughness, and pore spacing affects the performance of the MBBR system, analysis of surface traces and these parameters are important [11] [14] [17]. Different bacteria exist and the value of their average sizes must be less than the value of the surface roughness of the biofilter in order to ensure proper attachment to the surface. The average diameters of spherical and rod-shaped bacteria are $0.5-2.0 \mu \mathrm{m}$ and $0.25-1.0 \mu \mathrm{m}$ respectively [18]. Powder metallurgy is also used in the fabrication of carriers but the dynamic properties of the carriers will be hindered and this cannot be used in the MBBR system [19]. In this research, additive manufacturing of the biofilm carrier media through fused deposition modelling (FDM) technique is adopted. This method is chosen for the manufacture of biofilters because it is the most feasible additive manufacturing technique [20]. Authors in, [9] [11] [17] used 3D printing for the manufacture of their carrier media. Likewise, the computer-aided design (CAD) data obtained from the drawing allows modifications of the geometry and size to obtain carriers with different SSA which is one of the key reasons why FDM is preferred. Furthermore, the designed carrier media should have a void ratio of $60 \%-90 \%$ which is expressed as the ratio of the volume of voids to the volume of the solid biofilter [21]. In this study, PP pellets were extruded to make standard 3D printing filaments of $2.85 \mathrm{~mm}$ in diameter. These filaments were then used to make the biofilm carrier media through $3 \mathrm{D}$ printing technique which 
produces a high surface roughness on the carriers as compared to other manufacturing techniques like injection molding, powder metallurgy, and extrusion. This high surface roughness will enhance the microorganisms to easily attach themselves to the surface of the carriers.

Although research has been conducted in the design of biofilters, less work has been done in developing a mathematical model and governing equations for the design of the K3 Kaldnes and MB3 media. Moreover, determining parameters like the SSA, SA, and the volume of a biofilter empirically is difficult, and most manufacturers use computer software to design carriers and obtain these parameters directly from the software. From this developed model, manufacturers will be able to determine the SSA of a cylindrically shaped carrier media before designing it in the software. The model will assist in optimizing and designing a biofilm carrier of any size and shape. Moreover, a mathematical model and governing equations were developed which can be used to calculate the SSA of any cylindrically shaped carrier. Governing equations were also obtained for these carrier media. The developed model for these media will help the designer and manufacturer to predetermine the SSA of any hand-sketched carrier drawing before using the available software for designing and determining the respective SSA.

\section{Materials and Methods}

Figure 1 shows the flowchart of the overall methodology. First is the selection of the best plastic material which was done with the aid of CES Edupack 2019 software. Recycling of these plastics to produce pellets was done by Mr. Green Africa located in Nairobi, Kenya. The production of the $2.85 \mathrm{~mm}$ diameter filament was achieved using the single-screw extruder. The model development comprises mathematical and analytical formulas used in determining the SSA, SA and volume of the biofilter empirically. With the developed model, the design of these biofilm carriers was done using SolidWorks. Finally, the CAD data obtained from the software was transferred to the Ultimaker S3 for 3D printing of these biofilters.

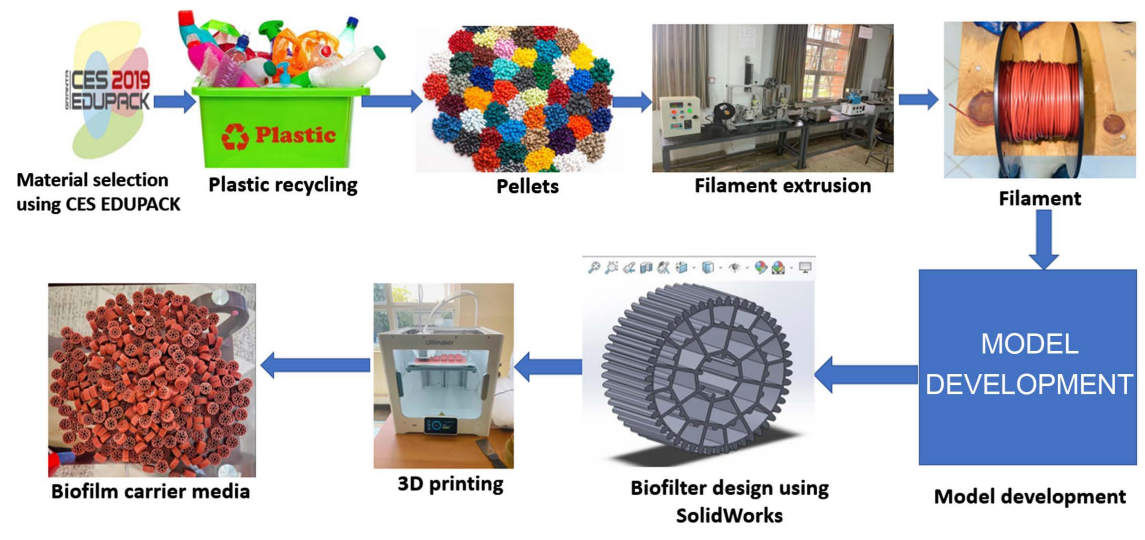

Figure 1. The flowchart of the overall methodology. 


\subsection{Selection of the Best Plastic Material}

CES EduPack was used in analyzing the various material properties. The material selected in this research was based on several factors including recyclability, density, acidity, melt flow rate, and chemical properties in wastewater. These properties are found in CES EduPack software and the material which fulfilled all these conditions was selected. The physical, mechanical, and chemical properties of PET, PP, LDPE, PVC, PS, ABS, and HDPE were examined. The density was considered as the most critical parameter and the plastic with a density of $10 \%$ lower than that of wastewater $\left(1000-1050 \mathrm{~kg} / \mathrm{m}^{3}\right)$ should be selected. In addition, the chemical properties of the material to be selected like toxicity, acidity, and reactivity the material should be conducive for biofilm growth. The melt flow rate and filament deposition of the plastics during printing should also be considered. In order to choose which material was suitable for this research, the elimination criteria method together with CES EduPack were adopted.

\subsection{Filament Production}

The single-screw extruder (SJ35, Zhangjiagang, China) that feeds the raw material into the three different controlled heating zones with a die nozzle of 2.85 $\mathrm{mm}$ diameter was used for filament production. PP pellets were extruded to make filaments of $2.85 \mathrm{~mm}$ diameter. The automatic metering unit sensor controls the speed of the hauling-stepping motor and filament winding control unit to give a $2.85 \mathrm{~mm}$ standard diameter filament. By using the manual means, random starting speeds for the screw extrusion speed, filament roller and winding speeds were chosen. Figure 2 below shows the SJ35 filament production line. First, the nozzle, barrel and feed cooling sections were first preheated to a set temperature of $180^{\circ} \mathrm{C}, 170^{\circ} \mathrm{C}$, and $60^{\circ} \mathrm{C}$ respectively. These temperatures were selected based on the manufacturer's manual for the extrusion of PP pellets [4]. The machine was initially preheated so as to reduce blockage and to speed up the input material to melting process. In order to push the melted material up to

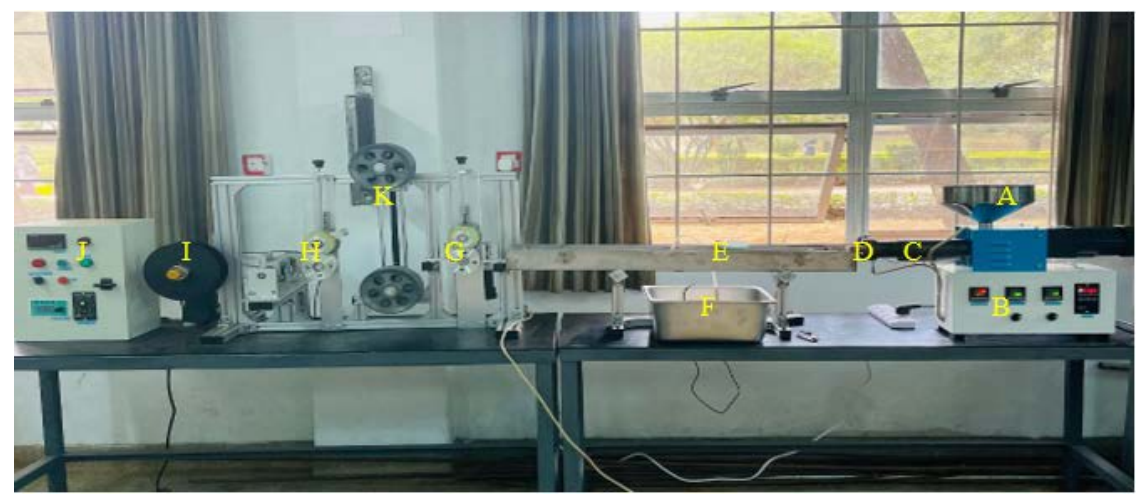

Figure 2. The SJ35 filament extruder. (A): Hopper; (B): SJ35 filament extruder control unit; (C): Barrel; (D): Mold; (E) and (F): Water cooling system; (G): Hauling-stepping motor control; $(\mathrm{H})$ : Automatic metering unit; (I): Winding reel; (J): Filament winding control unit; (K): Filament temporarily storage unit. 
the die nozzle the barrel screw speed was set at $10 \mathrm{rpm}$ forward rotation. For each feeding time, a pre-weighed $200 \mathrm{~g}$ of granulated PP or HDPE pellets was fed into the barrel through the hopper when the preset temperatures were reached for the fabrication of these pellets. The water-cooling bath cools the temperature of the hot extruded filament which was then pulled off by the filament reducers at a speed of $200 \mathrm{~mm} / \mathrm{s}$. Finally, the extruded filament was wound up and spooled on the spooler rotating at a speed of $100 \mathrm{~mm} / \mathrm{s}$ with the help of filament storage rollers. In order to obtain acceptable diameter ranges, the filament extrusion processing parameters were adjusted manually by changing the rotation speeds and temperatures and automatically by using the metering unit.

\subsection{Model Development and SSA Calculation for MB3 Media}

In deriving the governing equations for the MB3 media and K3 Kaldnes, the relation between radius and the rest of the internal geometries and cavities were determined. The developed model parameters include feature thickness, nozzle size, and the passage diameter which were considered in setting up the models. The most common available divisions and geometries of the internal cavities are those in which the internal walls form a cross or alveolar structure. The external walls are sometimes covered with fins to reduce friction between the carrier and the walls of the reactor [7] [15] [16] [21] [22]. The 3D printed carrier media were used in the derivation of the model with the help of dimensions obtained from SolidWorks. In order to determine the SA, the media was subdivided into several sections then their respective SA was calculated. These SA were then summed up to give the overall total SA of the media.

\subsection{Design of Carrier Media}

From the group of cylindrically shaped carriers, the MB media and $\mathrm{K}$ families are widely known. It is easier to derive mathematical relations and governing equations for these shapes due to their simple design. Analytical models for complex designs carriers can also be developed based on their geometry. Thus, the MB3 media and the K3 Kaldnes designs were selected. These were designed based on the existing commercial media carriers. From the developed model, a 2D hand sketch of these carriers was done with respect to the constraints like the passage diameter which must be more than $2.5 \mathrm{~mm}$, the thickness of the nozzle which should be more than $0.1 \mathrm{~mm}$ based on the smallest printer nozzle available [23]. The SSA of these carriers were then calculated based on the model results. These drawings were then designed using SolidWorks 2020 software and saved in STL (Standard Tessellation Language or Stereolithography) format. Their SSA, volume, and surface areas were also determined directly from the software.

\subsection{D Printing of Biofilm Carrier Media}

The dual extruder Ultimaker S3 (Zaltbommel, Netherlands) was used for the 3D 
printing of the carrier media. The printing parameters like the infill density, layer height, printing temperatures were adjusted using the Ultimaker Cura 4.8.0 open-source software. Recommended process parameters were obtained from the user's manual [24]. These included the temperature, infill density, and others which were adjusted to suit the processing conditions for the PP material [4] [25] [26] [27]. Packing tape (sumo tape) was used to ensure sufficient adhesion of the printed material onto the printing bed during the process. Smaller nozzle diameters are preferred for the printing of small objects as they ensure adequate infill percentage, thus $0.4 \mathrm{~mm}$ which was the smallest available diameter was used during the printing process. In order to analyze the surface traces and surface roughness of the biofilter, the Phase II SRG-4000 surface roughness tester (Penn Tool Co, USA) was used. The values were determined using the centre line average method to give $R_{a}$ values, which is known as the arithmetic average roughness. In order to achieve this, the biofilter was divided into four different sections, the cross-section, the lateral view, the outermost feature crest, and the outermost feature trough.

\section{Results and Discussion}

\subsection{Selection of Best Plastic Material}

Table 1 shows the properties of various materials used in the selection criteria. The material which fulfilled all the four conditions was selected. The recyclability of these thermoplastics showed that they could all be recycled. Additionally, their durability in wastewater was excellent. Although PP, HDPE, and PVC had excellent chemical resistance and durability in wastewater, PVC was not selected due to extremely high density which would result in continuously sinking biofilters. Clearly, only PP and HDPE were selected based the selection criteria and with emphasis on density.

In order to select between PP and HDPE, granulated pellets of recycled PP and HDPE (supplied by Mr. Green Africa, Nairobi, Kenya) were further analyzed. Table 2 shows material properties of these pellets.

Table 1. Selection criteria and material properties for thermoplastics.

\begin{tabular}{cccc}
\hline Material & Density & $\begin{array}{c}\text { Chemical Resistance } \\
\text { in wastewater }\end{array}$ & Conclusion \\
\hline PP & $900-909$ & Excellent & Selected \\
PET & $1290-1390$ & Good & Not selected \\
HDPE & $952-965$ & Excellent & Selected \\
ABS & $1020-1080$ & Poor & Not selected \\
LDPE & $917-932$ & Good & Not selected \\
PVC & $1450-1560$ & Excellent & Not selected \\
PS & $1040-1050$ & Good & Not selected \\
\hline
\end{tabular}


Table 2. Material properties of PP and HDPE used in the study.

\begin{tabular}{|c|c|c|c|c|c|c|}
\hline \multirow[b]{2}{*}{ Material } & \multicolumn{2}{|c|}{ Bulk density $\left(\mathrm{g} / \mathrm{cm}^{3}\right)$} & \multirow{2}{*}{$\begin{array}{l}\text { Humidity } \\
(\%)\end{array}$} & \multirow{2}{*}{$\begin{array}{l}\text { Pellet } \\
\text { diameter } \\
(\mathrm{mm})\end{array}$} & \multirow{2}{*}{$\begin{array}{l}\text { Pellet } \\
\text { width } \\
(\mathrm{mm})\end{array}$} & \multirow{2}{*}{$\begin{array}{c}\text { Melt } \\
\text { flow rate } \\
(\mathrm{g} / 10 \mathrm{~min})\end{array}$} \\
\hline & AS-Man & $\begin{array}{c}\text { Lab } \\
\text { Results }\end{array}$ & & & & \\
\hline $\begin{array}{c}\text { Recycled } \\
\text { PP }\end{array}$ & 0.574 & 0.590 & 0.137 & 5.036 & 2.016 & $\begin{array}{l}33.8 \text { with } 500 \mathrm{~g} \\
\text { weight at } 230^{\circ} \mathrm{C}\end{array}$ \\
\hline $\begin{array}{l}\text { Recycled } \\
\text { HDPE }\end{array}$ & 0.618 & 0.621 & 0.143 & 4.54 & 3.21 & $\begin{array}{l}1.53 \text { with } 500 \mathrm{~g} \\
\text { weight at } 230^{\circ} \mathrm{C}\end{array}$ \\
\hline
\end{tabular}

In order to choose the best material between PP and HDPE, filaments of these two materials were manufactured and used for $3 \mathrm{D}$ printing. It was noticed that the melt flow rate of the HDPE was lower than that of PP. With this low level of the melt flow rate, the deposition of HDPE material during 3D printing was difficult. With this reason, PP was selected as the best plastic material.

\subsection{Filament Production Using Recycled PP}

In order to fabricate filaments within this acceptable range of $2.85 \mathrm{~mm}( \pm 0.05)$, the automatic or manual techniques were adopted. The automatic metering unit sensor was used to control the speed of the hauling-stepper motor and filament winding control unit to give a $2.85 \mathrm{~mm}$ standard diameter filament which was used for the additive manufacturing process. By using the manual means, random starting speeds for the screw extrusion speed, filament roller and winding speeds were chosen. The diameter of the filaments fabricated was within the acceptable standard diameter with tolerance of $2.85 \mathrm{~mm}( \pm 0.05)$ [4]. This is also necessary as uniform filament feeding during the $3 \mathrm{D}$ printing process with the Ultimaker S3 is key to the printing process. As the filament was being extruded, it was passed through the cooling system, to the hauling-stepping motor, to the winding reel, then finally to the temporarily filament storage unit. The screw extrusion speed was set and varied from 18 to $20 \mathrm{rpm}$ to provide a uniform filament diameter of $2.85 \mathrm{~mm}$. After the extrusion process, the fabricated filament was channeled through the filament storage rollers and wound up on a spooler at a controlled speed of $160 \mathrm{~mm} / \mathrm{s}$. In order to confirm the uniform $2.85 \mathrm{~mm}$ diameter, a vernier caliper was used as shown in Figure 3.

\subsection{Model Development and SSA Determination}

\subsubsection{Mathematical Model and SSA Calculations for the MB3 Media}

In deriving the general equation to calculate the SSA and volume of the media, the biofilm carrier was subdivided into several sections, see Figure 4 and their individual surface areas were calculated.

Considering the shape of the MB3 media to be cylindrical and where:

The top features surface area: $A_{t f}$, biofilter top surface gap area: $A_{t s g o}$, biofilter top surface gap area: $A_{t s g i}$, side surface area for circle: $A_{c s}$, main polygon outer surface determination: $A_{p o}$, semicircular feature surface area: $A_{f c}$, main 


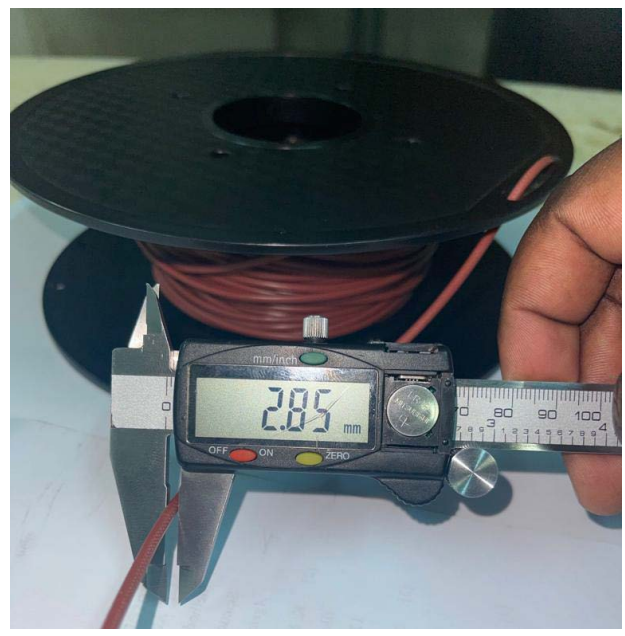

Figure 3. Verification of the filament diameter.

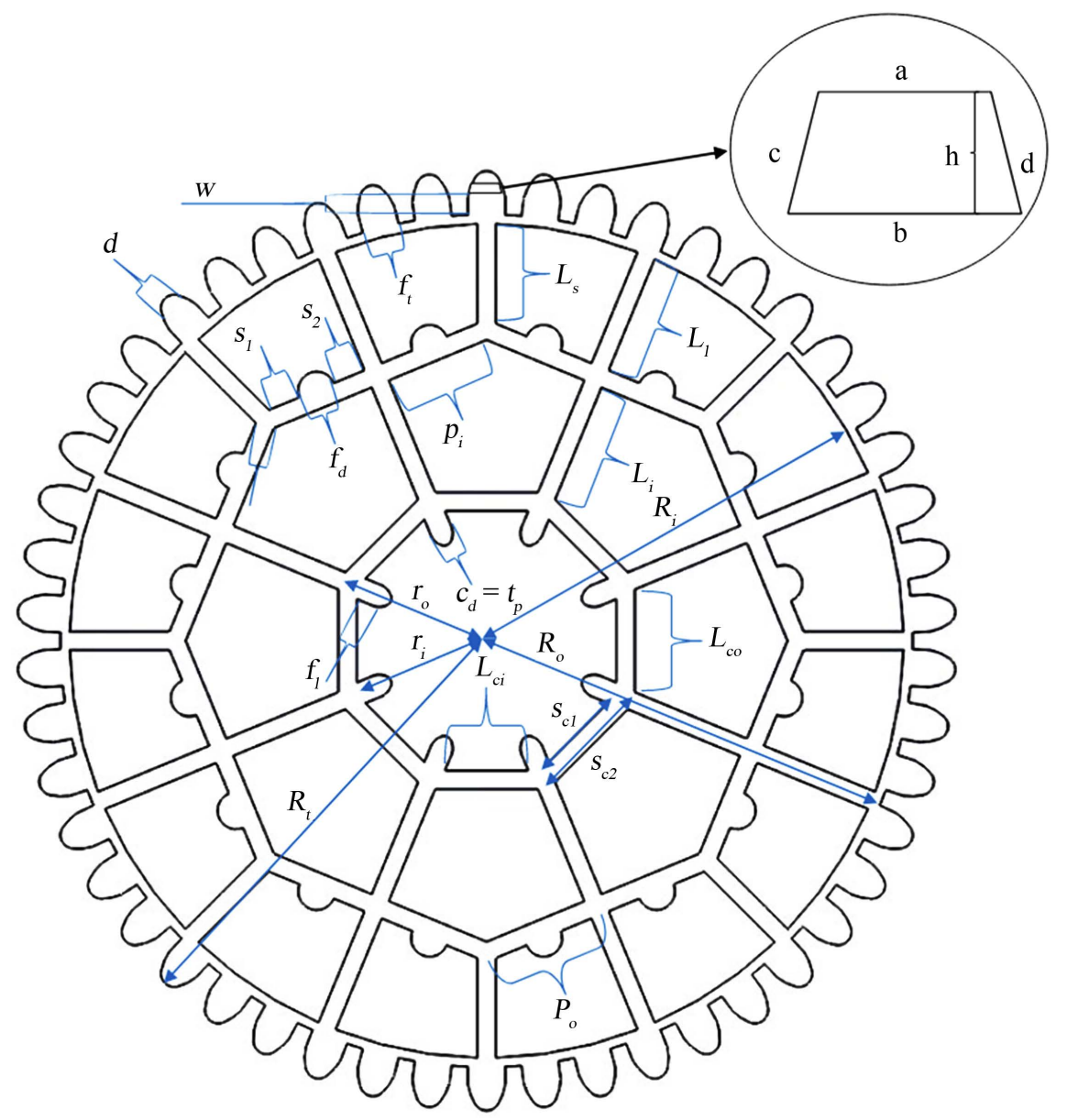

Figure 4. 2D annotations for the derivation of the general equation for the MB3 media.

polygon face surface: $A_{p s}$, semi-circle feature face area: $A_{c f}$, short support surface area $A_{L s}$, long support surface area $A_{L l}$, main polygon inner surface areas $A_{p i}$, center polygon supports inside surface area $A_{p c i s}$, center polygon supports side area $A_{p c s s}$, center polygon outer surface area $A_{p c o}$, center polygon 
inner surface area $A_{p c i}$, center polygon side surface area $A_{p c s a}$, center polygon inner features surface area rectangular $A_{p c i r}$, center polygon inner features surface semicircle $A_{p c i r}$, center polygon inner features surface side area of semicircle $A_{p c i c}$, center polygon inner features side surface areas rectangular: $A_{p c i s r}$.

The biofilter total surface area is given by summing up all the above areas. Thus,

$$
\begin{aligned}
A_{T}= & A_{t f}+A_{p c i r}+A_{t s g i}+A_{t s g o}+A_{c s}+A_{p o}+A_{f c}+A_{p s}+A_{c f}+A_{L s}+A_{L l} \\
& +A_{p c i s}+A_{p c s s}+A_{p c i s}+A_{p c i}+A_{p c o}+A_{p c s a}+A_{p c i r}+A_{p c i c}+A_{p c i s r}
\end{aligned}
$$

Volume is given by face surface area of media multiplied by its height $(h)$

$$
V_{M B 3}=A_{T F S A} \times h \text {. }
$$

The SSA is given by

$$
S S A_{M B 3}=\frac{S A_{M B 3}}{V_{M B 3}}
$$

Moreover, the void ratio is given by

$$
V_{R M B 3}=\frac{V_{S}-V_{M B 3}}{V_{S}}
$$

Volume of a cylinder

$$
V_{S}=\pi r^{2} h
$$

where $V_{S}$ and $V_{M B 3}$ represent the volume of the solid cylinder and volume of the MB3 media respectively.

Considering the aspect of clogging, the minimum passage diameter should be more than $2.5 \mathrm{~mm}$. Thus, the values of $\left(s_{1}+s_{2}+f_{d}\right), L_{s}, L_{i}, L_{c 0}$ must be more than $2.5 \mathrm{~mm}$ to minimize clogging.

\subsubsection{Model Development and SSA Calculation for K3 Kaldnes Media}

Similarly, in deriving the general equation to calculate the SSA and volume of the K3 Kaldnes media, the biofilm carrier was also subdivided into several sections as shown in Figure 5 and their individual surface areas calculated.

The top feature surface area: $A_{t f}$, bio-filter top surface gap area: $A_{t s g o}$, biofilter inner surface gap area: $A_{t s g i}$, side Surface Area for circle: $A_{c s}$, main polygon outer surface area determination $A_{p o}$, semicircular feature surface area: $A_{f c}$, main polygon face surface $A_{p s}$, semi-circle feature face area $A_{c f}$, the joint isosceles triangle surface area: $A_{J I T}$, short support surface area $A_{L S}$, long Support surface area $A_{L l}$, main polygon inner surface areas $A_{p i}$, center polygon supports inside surface area $A_{p c i s}$, center polygon supports side area $A_{p c s s}$, center polygon outer surface area $A_{p c o}$, center polygon inner surface area $A_{p c i}$, center polygon side surface area $A_{p c s a}$, center shape joint isosceles side area $A_{p c t}$.

The K3 Kaldnes total surface area is obtained by summing up all the individual areas and is given by 


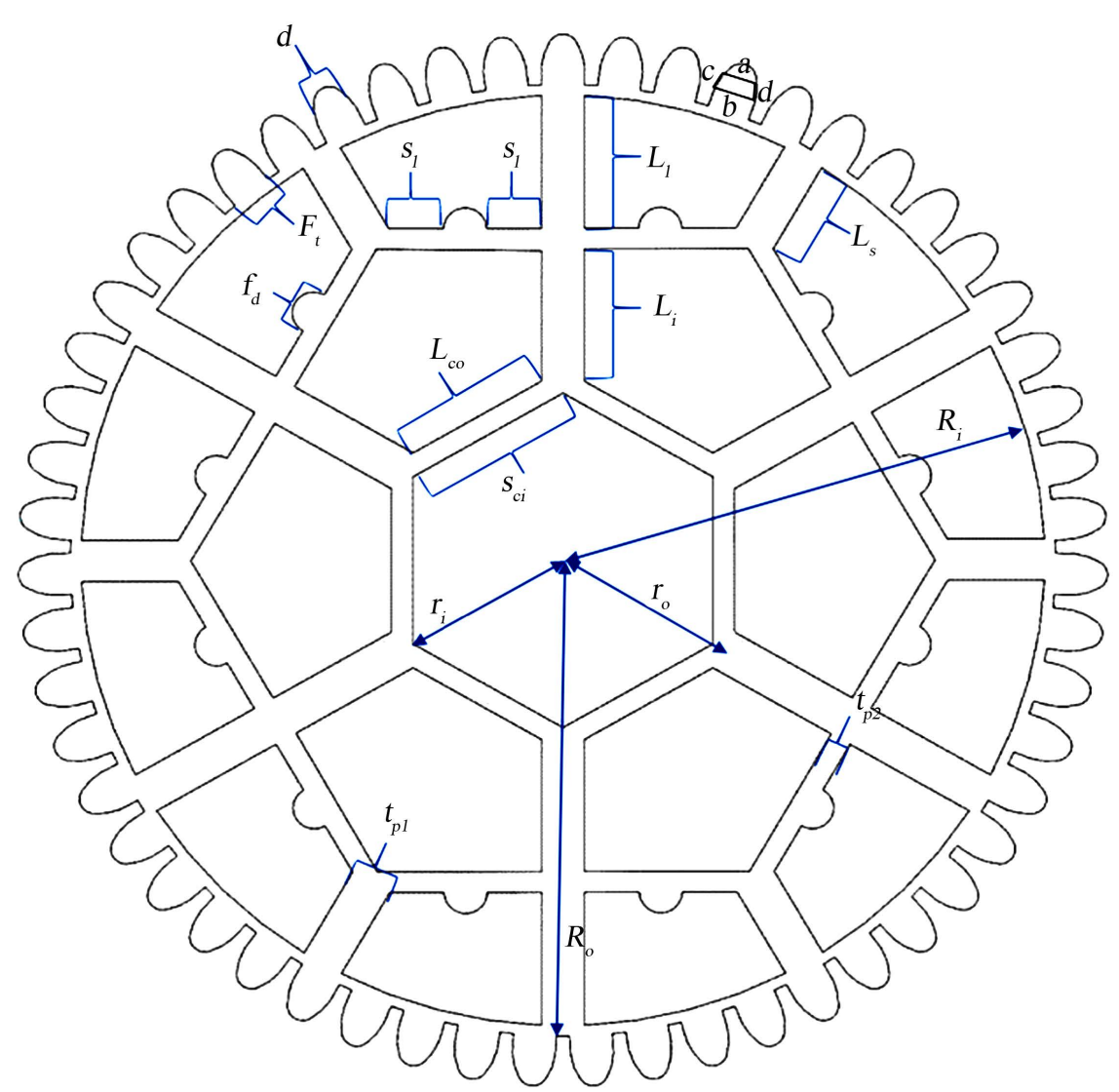

Figure 5. 2D annotations for the derivation of the general equation for the K3 Kaldnes media.

$$
\begin{aligned}
A_{T}= & A_{t f}+A_{t s g o}+A_{t s g i}+A_{c s}+A_{p o}+A_{f c}+A_{p s}+A_{c f}+A_{J I T}+A_{L s} \\
& +A_{L l}+A_{p i}+A_{p c i s}+A_{p c s s}+A_{p c o}+A_{p c i}+A_{p c s a}+A_{p c t}
\end{aligned}
$$

Volume is given by face surface area of the K3 Kaldnes multiplied by the height $(h)$.

$$
V_{B v}=A_{T F S A} \times h
$$

Moreover, the void ratio is given by

$$
V_{R K 3}=\frac{V_{S}-V_{K 3}}{V_{S}}
$$

Volume of a cylinder

$$
V_{S}=\pi r^{2} h
$$

where $V_{S}$ and $V_{K 3}$ represent the Volume of the solid cylinder and volume of the K3 Kaldnes media.

Likewise, considering the aspect of clogging, the minimum passage diameter should be more than $2.5 \mathrm{~mm}$. Thus, the values of $\left(s_{1}+s_{2}+f_{d}\right), L_{s}, L_{i}$ and $L_{c 0}$ must be more than $2.5 \mathrm{~mm}$ to minimize clogging.

In order to determine the accuracy of the model, the errors in SSA of the model result were calculated with respect to those obtained from the Solid- 
Works.

The \% error

$$
E=\frac{\text { SSA from SolidWorks }- \text { SSA from Model }}{\text { SSA from SolidWorks }} \times 100
$$

Table 3 shows the SA, diameter, volume, void ratio, height, and the minimum passage diameter for the MB3 and K3 Kaldnes media as guided by SolidWorks.

The K3 Kaldnes had a void ratio of $66.39 \%$ and the MB3 media had a void ratio of $67.14 \%$. Generally, void ratios for these carriers should be between $60 \%$ $90 \%$. These void ratios are within the acceptable range of the design of carrier media as reported by Bengston [21]. In the selection of the best plastic material, recycled PP pellets were selected for the fabrication of $2.85 \mathrm{~mm}$ diameter filaments based on their physical, chemical, mechanical properties, and melt flow rate during the printing process. The density of the printed PP media was measured using the Archimedean immersion method and found to be $0.590 / \mathrm{cm}^{3}$. Two different designs, the MB3 media and K3 Kaldnes were both printed using Ultimaker S3. The SSA of MB3 media was higher compared to the K3 Kaldnes because the inner feature of MB3 is octagonal whereas the latter is hexagonal. The volume was calculated by multiplying the SSA with the height. The SSA obtained from model development was compared to that obtained from SolidWorks. Using Equation 9, the errors obtained were $0.34 \%$ for the K3 Kaldnes and $0.76 \%$ for the MB3 media, see Table 4 .

\subsection{D Printed Carrier Media and Surface Characterization}

The two biofilm carriers MB3 and K3 Kaldnes were printed with the Ultimaker S3 from the $2.85 \mathrm{~mm}$ diameter recycled PP filament. The MB3 media took 32 minutes to complete printing while the $\mathrm{K} 3$ Kaldnes took 25 minutes. This is mainly due to feature differences in the two designs. The printed K3 Kaldnes and MB3 media showed a high level of surface roughness which is important in

Table 3. Specifications of the K3 Kaldnes and MB3 media adopted for 3D printing.

\begin{tabular}{ccccccc}
\hline Type of media & $\begin{array}{c}\text { Diameter } \\
(\mathrm{mm})\end{array}$ & $\begin{array}{c}\text { Height } \\
(\mathrm{mm})\end{array}$ & $\begin{array}{c}\text { Volume } \\
\left(\mathrm{cm}^{3}\right)\end{array}$ & $\begin{array}{c}\text { Surface } \\
\text { Area } \\
\left(\mathrm{cm}^{2}\right)\end{array}$ & $\begin{array}{c}\text { Void } \\
\text { Ratio } \\
(\%)\end{array}$ & $\begin{array}{c}\text { Minimum } \\
\text { passage } \\
\text { diameter }(\mathrm{mm})\end{array}$ \\
\hline MB3 media & 25.00 & 12.00 & 1.835 & 66.654 & 67.14 & 3.63 \\
K3 Kaldnes & 25.00 & 12.00 & 2.049 & 61.139 & 66.398 & 3.60 \\
\hline
\end{tabular}

Table 4. SSA of the MB3 media and K3 Kaldnes from both the software and model results.

\begin{tabular}{cccc}
\hline Type of carrier & $\begin{array}{c}\text { SSA from } \\
\text { SolidWorks } \mathbf{~}^{2} / \mathrm{m}^{3}\end{array}$ & $\begin{array}{c}\text { SSA from } \\
\text { model developed }\end{array}$ & $\begin{array}{c}\text { Error } \\
(\%)\end{array}$ \\
\hline K3 Kaldnes & 2994.04 & 2983.84 & 0.34 \\
MB3 Media & 3632.37 & 3660.19 & 0.76 \\
\hline
\end{tabular}


the design phase of the biofilter [11] [14] [17]. From the several primary printing parameters, the infill density was set to $100 \%$ to obtain a fine and more denser media carrier (Figure 6).

The values for the surface roughness $\left(R_{a}\right)$ were determined using the centre line average method. Figures $7(\mathrm{~A})-(\mathrm{C})$ show the $R_{a}$ values for various sections in MB3 carrier media.

The cross-section view shows the inner features and the average value for $R_{a}$ was obtained to be $16.01 \mu \mathrm{m}$. The outermost feature crest and trough had the same $R_{a}$ value of $13.00 \mu \mathrm{m}$. The lateral or horizontal $R_{a}$ value was obtained to be $3.90 \mu \mathrm{m}$. Table 5 shows the $R_{a}$ values for the different sections of MB3 carrier media.

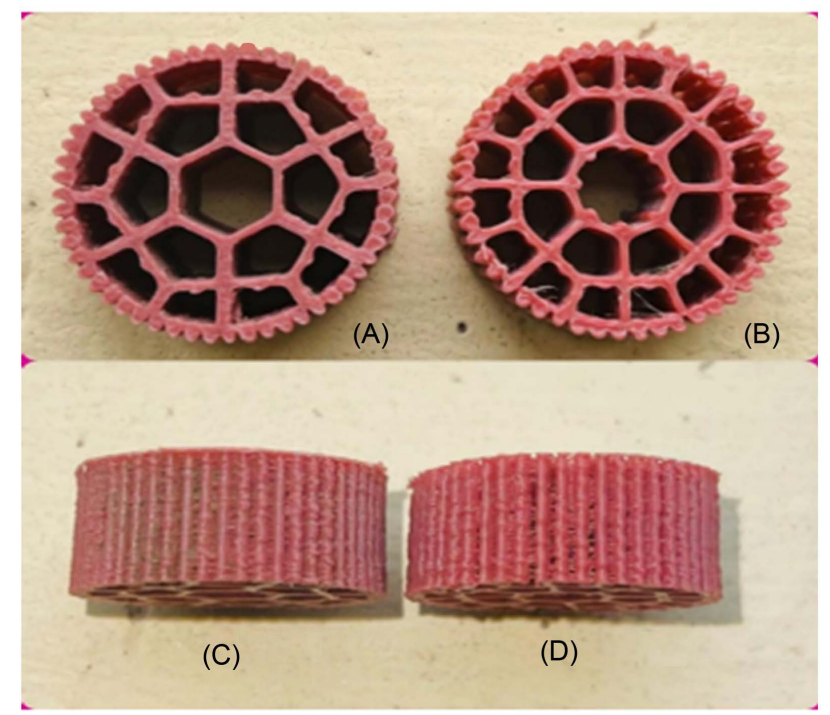

Figure 6. 3D printed biofilm carrier media (A) and (B) are the top views of the $\mathrm{K} 3$ Kaldnes and MB3 media respectively, (C) and (D) shows the corresponding side views of the same carrier media in that order.

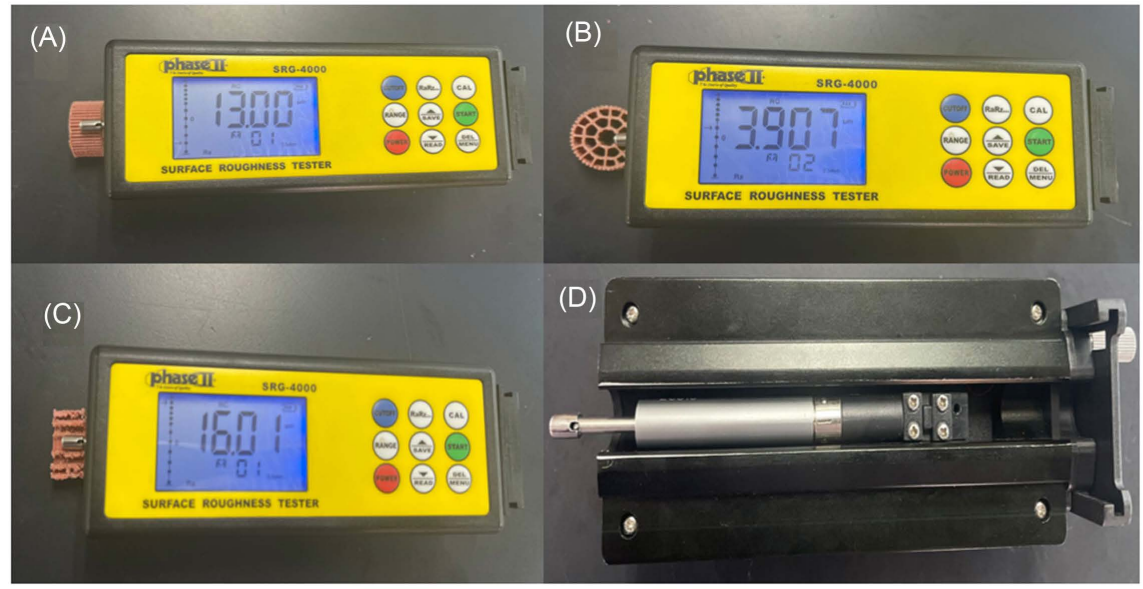

Figure 7. (A): $R_{a}$ value of the outermost features; (B): $R_{a}$ value of the lateral view section; (C): $R_{a}$ value of the cross-section; (D): Bottom view of the SRG-4000 surface roughness tester. 
Table 5. Surface roughness values for different sections of the biofilter.

\begin{tabular}{ccc}
\hline S/N & Section of biofilter & $\boldsymbol{R}_{a}$ value $(\mu \mathrm{m})$ \\
\hline $\mathbf{1}$ & Cross section & 16.01 \\
$\mathbf{2}$ & Lateral view section & 3.90 \\
$\mathbf{3}$ & Outermost feature crest & 13.00 \\
$\mathbf{4}$ & Outermost feature trough & 13.00 \\
\hline
\end{tabular}

\section{Conclusions}

This study shows that analytical models can be developed for cylindrically shaped carriers. Moreover, plastics can be recycled to make filaments for the printing of biofilm carrier media. The following conclusions can be drawn from this study:

1) A mathematical model was developed for the derivation and calculation of the surface area, volume and SSA for both the MB3 and K3 Kaldnes media. The model developed will help the designer and manufacturer in geometry alterations to obtain several shapes, sizes and different dimensions before designing it in the available software.

2) The recycling of plastics will help reduce the level of plastic pollution and this recycling of plastic to produce filaments for 3D printing of biofilm carrier will additionally help in the efficient treatment of wastewater.

3) The minimum value for the surface roughness was $3.90 \mu \mathrm{m}$ for the MB3 carrier media which was higher than the average size of the bacteria $(0.5-1.0$ $\mu \mathrm{m})$, thus the microorganisms can easily attach themselves to the surface of the media.

\section{Acknowledgements}

The authors acknowledge the financial support provided by the Pan African University through the Institute of Basic Sciences, Technology \& Innovation (PAUSTI) and Japan International Cooperation Agency (JICA).

\section{Conflicts of Interest}

The authors declare no conflicts of interest regarding the publication of this paper.

\section{References}

[1] Abdel-raouf, M.E., Maysour, N.E. and Farag, R.K. (2019) Wastewater Treatment Methodologies, Review Article. International Journal of Environment \& Agricultural Science, 3, 18.

[2] Mikula, K., Skrzypczak, D., Izydorczyk, G., Warcho, J. and Moustakas, K. (2021) 3D Printing Filament as a Second Life of Waste Plastics-A Review. Environmental Science and Pollution Research, 28, 12321-12333. https://doi.org/10.1007/s11356-020-10657-8

[3] Kreiger, M.A., Mulder, M.L., Glover, A.G. and Pearce, J.M. (2014) Life Cycle Analysis of Distributed Recycling of Post-Consumer High Density Polyethylene for 3-D 
Printing Filament. Journal of Cleaner Production, 70, 90-96. https://doi.org/10.1016/j.jclepro.2014.02.009

[4] Polline, M., Mutua, J.M., Mbuya, T.O. and Ernest, K. (2021) Recipe Development and Mechanical Characterization of Carbon Fibre Reinforced Recycled Polypropylene 3D Printing Filament. Open Journal of Composite Materials, 11, 47-61. https://doi.org/10.4236/ojcm.2021.113005

[5] Proano-pena, G., Id, A.L.C. and Id, D.M.B. (2020) Analysis of Very-High Surface Area 3D-Printed Media in a Moving Bed Biofilm Reactor for Wastewater Treatment. PLoS ONE, 15, e0238386. https://doi.org/10.1371/journal.pone.0238386

[6] Elliott, O., et al. (2017) Design and Manufacturing of High Surface Area 3D-Printed Media for Moving Bed Bioreactors for Wastewater Treatment. Journal of Contemporary Water Research \& Education, 160, 144-156. https://doi.org/10.1111/j.1936-704X.2017.03246.x

[7] Spoerk, M., Holzer, C. and Gonzalez-Gutierrez, J. (2020) Material Extrusion-Based Additive Manufacturing of Polypropylene: A Review on How to Improve Dimensional Inaccuracy and Warpage. Journal of Applied Polymer Science, 137, 1-16. https://doi.org/10.1002/app.48545

[8] Barna, J., Torok, J., et al. (2012) Special Materials Used in FDM Rapid Prototyping Technology Application. INES 2012: IEEE 16th International Conference on Intelligent Engineering Systems. Proceedings, Lisbon, 13-15 June 2012, 578.

[9] Martínez-huerta, G., Prendes-gero, B., Ortega-fernández, F. and Mesa-fernández, J.M. (2009) Design of a Carrier for Wastewater Treatment Using Moving Bed Bioreactor. Proceedings of the 2 nd International Conference on Environmental and Geological Science and Engineering, Oviedo, 2019, 44-49.

[10] Al-Amshawee, S.K., Yunus, M.Y. and Azoddein, A.A. (2020) A Novel Microbial Biofilm Carrier for Wastewater Remediation. IOP Conference Series: Materials Science and Engineering, 736, Article ID: 072006.

https://doi.org/10.1088/1757-899X/736/7/072006

[11] Ødegaard, H., Gisvold, B. and Strickland, J. (2018) The Influence of Carrier Size and Shape in the Moving Bed Biofilm Process. Water Science \& Technology, 41, 383-391. https://doi.org/10.2166/wst.2000.0470

[12] Majid, A. (2019) Application of Lab-Scale MBBR to Treat Industrial Wastewater using K3 Carriers: Effects of HRT, High COD Influent, and Temperature. International Journal of Environmental Sciences \& Natural Resources, 20, 35-42. https://doi.org/10.19080/IJESNR.2019.20.556031

[13] Piculell, M. (2016) New Dimensions of Moving Bed Biofilm Carriers: Influence of Biofilm Thickness and Control Possibilities. Department of Chemical Engineering, Lund University, Lund.

[14] Guerdat, T.C., Losordo, T.M., Classen, J.J., Osborne, J.A. and Delong, D.P. (2010) Aquacultural Engineering: An Evaluation of Commercially Available Biological Filters for Recirculating Aquaculture Systems. Aquacultural Engineering, 42, 38-49. https://doi.org/10.1016/j.aquaeng.2009.10.002

[15] Zhou, X.H., Shi, H.C. and Qiu, Y.Q. (2008) Inner-Profiles of a Spherical Bio-Carrier Determined by Microelectrodes. Biochemical Engineering Journal, 39, 28-36. https://doi.org/10.1016/j.bej.2007.08.010

[16] Al-Amshawee, S. and Yunus, M.Y.B.M. (2021) Geometry of Biofilm Carriers: A Systematic Review Deciding the Best Shape and Pore Size. Groundwater for Sustainable Development, 12, Article ID: 100520.

https://doi.org/10.1016/j.gsd.2020.100520 
[17] Felföldi, T., et al. (2015) Texture and Type of Polymer Fiber Carrier Determine Bacterial Colonization and Biofilm Properties in Wastewater Treatment. Chemical Engineering Journal, 264, 824-834. https://doi.org/10.1016/j.cej.2014.12.008

[18] Different Size, Shape and Arrangement of Bacterial Cells. https://microbiologyinfo.com/different-size-shape-and-arrangement-of-bacterial-cells

[19] Kruzhanov, V. (2019) Modern Manufacturing of Powder-Metallurgical Products with High Density and Performance by Press-Sinter Technology. https://doi.org/10.1007/s11106-018-0002-1

[20] Vyavahare, S., Teraiya, S. and Kumar, S. (2020) Fused Deposition Modelling: A Review. Rapid Prototyping Journal, 26, 176-201. https://doi.org/10.1108/RPJ-04-2019-0106

[21] Bengtson, H. (2017) CE-084 Wastewater Treatment II MBBR, No. 833.

[22] Dong, Y., Fan, S., Shen, Y., Yang, J., Yan, P. and Chen, Y. (2015) A Novel Bio-Carrier Fabricated Using 3D Printing Technique for Wastewater Treatment. Scientific Reports, 5, Article No. 12400. https://doi.org/10.1038/srep12400

[23] Smallest Nozzle for 3D Printing. Less than $0.2 \mathrm{~mm}$, Possible? TheMechNinja. https://themechninja.com/07/smallest-nozzle-for-3d-printing-less-than-2-mm

[24] Ultimaker S3 and Ultimaker S5 Installation and User Manual.

[25] Al-Qodah, Z., Al-Qudah, Y. and Omar, W. (2019) On the Performance of Electrocoagulation-Assisted Biological Treatment Processes: A Review on the State of the Art. Environmental Science and Pollution Research, 26, 28689-28713. https://doi.org/10.1007/s11356-019-06053-6

[26] Su-ungkavatin, P., Thongnueakhaeng, W. and Chaiprasert, P. (2019) Simultaneous Removal of Sulfur and Nitrogen Compounds with Methane Production from Concentrated Latex Wastewater in Two Bioreactor Zones of Micro-Oxygen Hybrid Reactor. Journal of Chemical Technology \& Biotechnology, 94, 3276-3291. https://doi.org/10.1002/jctb.6139

[27] Ultimaker, P.P. (2018) Technical Data Sheet. 1-3. https://support.ultimaker.com/hc/en-us/articles/360012059859-The-Ultimaker-mat erial-technical-and-safety-data-sheets 